\title{
Variability among groups of nursing students' utilization of a technological learning tool for clinical skills training: An observational study
}

\author{
Cecilie Haraldseid ${ }^{*}$ Karina Aase \\ University of Stavanger, Stavanger, Norway
}

Received: November 22, 2016

DOI: $10.5430 /$ jnep.v7n7p66

\author{
Accepted: February 12, 2017 \\ Online Published: February 16, 2017 \\ URL: https://doi.org/10.5430/jnep.v7n7p66
}

\begin{abstract}
Background and objective: The use of technology has become the norm in nursing education. While technology has opened up for more flexible, active, student-focused teaching methods, its introduction has also brought challenges regarding its use and implementation. Recent literature has concentrated on how to best implement technology, but little attention has focused on observing student practices during technology use. Therefore, it is unknown how to optimize technology use within clinical skills training. The objective of this study was to investigate how groups of nursing students utilize a technology-based learning tool. Methods: An observational study with an exploratory design was implemented using video recordings as the data material. Results: The results indicated a high level of variability in nursing students' performance and ability to utilize a technological tool while working in groups. The variability during clinical skills training was associated with four factors: level of competence, motivation to learn, role clarification, and collaborative problem-solving skills.

Conclusions: The results of the study indicated variability in groups of nursing students' ability to employ a technological tool during a selected procedure-namely, wound care and dressing. These findings suggest that a set of implications for faculty members should be developed. Specifically, staff and students should be prepared prior to using technology by focusing on group dynamics, group composition, development of collaborative problem-solving skills, and role modeling.
\end{abstract}

Key Words: Nursing education, Educational technology, Clinical skills, Non-participant observation

\section{INTRODUCTION}

Faculty members are constantly attempting to find new ways to motivate and engage students in learning. ${ }^{[1,2]}$ In the field of nursing, the complexity of clinical skill learning ${ }^{[3]}$ and the shift towards student active learning methods has created a need to change the methods of teaching clinical skills. ${ }^{[4-6]}$ Embedding technological components in courses has become the norm in the development and implementation of new teaching methods; $;^{[7,8]}$ this is because there have been technological advances in the field. Technology-based learn- ing tools include, but are not limited to, the following: video lectures, web-based courses, high and low fidelity simulation, virtual patients, serious games, personal digital assistants, and podcasts. ${ }^{[9-14]}$ While active participation has increased, the use and implementation of technology has presented challenges to faculty members.

A considerable amount of research has addressed the challenges associated with technology implementation. The majority of the literature has focused on barriers to technology

*Correspondence: Cecilie Haraldseid; Email: cecilie.haraldseid@uis.no; Address: University of Stavanger, Stavanger, Norway. 
use by faculty members and students. Several studies have indicated that the provision of technology-based training, sufficient IT support, adequate accessibility, computer skills, and allocated time and resources are related to technology implementation. ${ }^{[15]}$ Additional obstacles include unreliable technology, which leads to frustration and wasted time in addition, faculty members reporting that it is challenging to keep up-to-date on available technologies. ${ }^{[2]}$ Research has examined attitudes toward technology; for instance, Petit dit Dariel and Wharrad ${ }^{[16]}$ found pedagogical beliefs, social networks, and academic culture influenced staff attitudes. They argued that skepticism and indifference toward technology are associated with a lack of use among nurse educators. The successful introduction of technology is also dependent on the motivation for its use. ${ }^{[17]}$ Studies have also compared the relations between perceived self-efficacy, technology-based methodology, and traditional methods. ${ }^{[9,18]}$ In addition, research indicates that faculty members should provide sound instructional design and usability testing to ensure positive user experiences. ${ }^{[19]}$

A common feature of the current research is the focus on participants' experience and beliefs regarding different beliefs concerning different technology-based tools, often limited to the implementation phase. Thus far, little attention has been paid to observing student practices when using technology. As most nursing faculty members have already integrated technology-based learning tools within their clinical skills training, the question now is how to optimize the use based on observations of groups of students employing the technology.

\section{Aim}

The aim of this study was to investigate how groups of nursing students utilized a technology-based learning tool in clinical skill training. Thus, two research questions were developed:

(1) How can nursing students' variability in performance when using a technological tool tailored for clinical skills training be mapped?

(2) Which factors influence groups of nursing students' ability to utilize a technological tool during clinical skills training?

\section{MethodS}

\subsection{Design}

An exploratory ${ }^{[20]}$ was conducted using video recordings to capture students' actions and practices, which provided researchers with access to the details of their social actions. In addition, video recordings allow researchers to conduct

Published by Sciedu Press multiple analytical steps without being present during data collection. ${ }^{[21]}$

\subsection{Setting}

The study was conducted with students in their second year of a Bachelors in Nursing degree at a Norwegian faculty. More specifically, the study was conducted during the compulsory clinical skills course. This course is taken during students' fourth semester and teaches 13 clinical skills (e.g., intramuscular injection, nasogastric tube insertion, wound care; for a more detailed account ${ }^{[22]}$ ). All skills are taught in a clinical skills laboratory (CSL) via nine, 3-hour, scenariobased training sessions. During each session, teachers lead a group of students through different scenarios. Students practice in small groups while the teacher supervises, asks questions, and answers questions. In addition, students have unlimited access to the CSL and are expected to engage in unsupervised training to master skills before the final exam. All students take a practical oral exam at the end of the course where they are tested on one of the 13 randomly chosen skills.

A set of interactive, technologically mediated, learning scenarios was developed to help the students prepare for the practical oral exam during their unsupervised training; these scenarios were based on the exam scenarios. The scenarios were mediated through a handheld portable tablet from Laerdal Medical called $\operatorname{SimPad}^{\circledR}$. The faculty already owned this technology, thereby making it accessible during students' unsupervised training. All second-semester students were offered a one-hour training session on the operation of the tablets at the beginning of the course. Then, the tablets were programmed with eight of the 13 exam scenarios; they were available in the CSL daily from 06:00 to 23:00. The technological learning material was presented as a checklist that outlined the different practical steps, thereby ensuring that the steps were practiced in a consecutive sequence. Students were asked questions and given feedback throughout the process. Each scenario required a group of three students: one student was the instructor, one was the patient, and one was the student practicing the skill. The instructor-student held the tablet, registered the actions on the tablet, followed the instructions on the tablet, and guided the other students through the scenario. The instructor-student helped the student practicing the scenario and prevented him/her from poor practice via the information on the tablet. Every action registered by the instructor-student was linked to a reaction (e.g., point out that an action is wrong and urge reconsideration; ask students to explain his/her action; provide additional information and ask for contraindications or for subsequent actions). The learning material consisted exclusively of text. 


\subsection{Ethical considerations}

The head of the nursing faculty and the Norwegian Social Science Data Service (ref. number: 36260) approved the study. All participants were given both written and oral in formation about the study, including the right to withdraw from the study at any point before, during, or after the video recording had taken place. Written informed consent was obtained from all participants prior to data collection. All data were stored in a secure location on a password-protected computer. Participants were informed that the aim of the video recording was to study their interactions with the technology and their group process, not an evaluation of their individual performance. All presented data are anonymized.

\subsection{Data material}

The data were derived from one of the 13 clinical skills scenarios-namely, wound care and dressing. There were practical reasons for choosing this scenario since it were developed using active student involvement in a previous study. ${ }^{[23]}$ The data included seven videos, from seven different groups (ranging from 20 to 33 minutes), totaling 221 minutes.

\subsection{Participants and data collection}

Data were collected in 2014 over a four-day period during the fourth week of the clinical skills course. This is when all
158 students took part in a training session on wound care and dressings. During this time, one of the rooms in the CSL was set up for video recording. The teachers informed all students about the ongoing study. After they participated in the first hour of the training session, participants were invited to contact the first author in the video recording room. Seven groups agreed to be video recorded, totaling 17 students (15 female and 2 male) who were all in their fourth semester. Groups consisted of two or three participants: three groups had three students and four groups had two students. The groups with two students used a mannequin as the patient and groups of three students used a student as the patient. The groups divided the roles among themselves. They were then handed the tablet with instructions to use as they saw fit; they only had to finish all sections of the scenario. The first author was located outside the room in case the students had any questions. All necessary equipment was located on a trolley within the room instead of the supply room; this was done to increase efficiency and reduce unnecessary movement during the scenario. Students were supplied with both necessary and unnecessary equipment, and they could choose what to use. Two stationery cameras were set up: one to capture an overview of the situation and one to capture the screen of the tablet to see the actions of the instructor (see Figure 1).

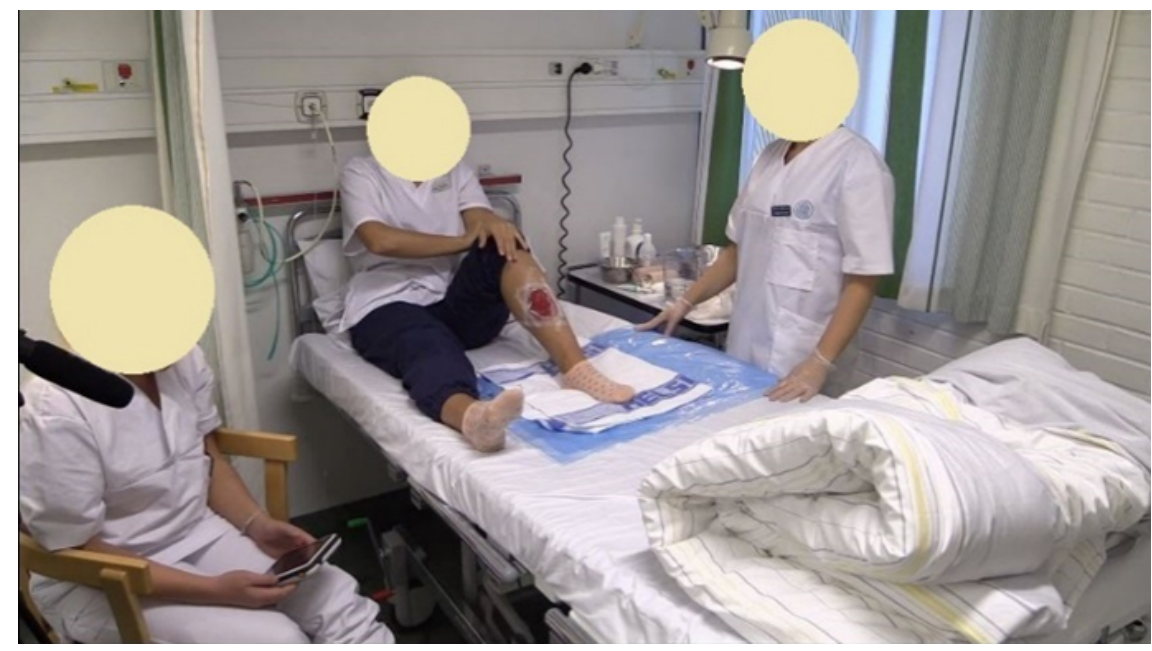

Figure 1. Overview of the video recording location

\subsection{Data analysis}

To address the research questions, the data analysis followed a two-step process: (1) map the group performance by scoring the scenarios, and (2) describe the factors influencing the groups' ability to utilize the technological tool. The recordings from the overview camera were analyzed, and the recordings from the second camera were used to clarify actions within certain video segments.

\subsubsection{Variability in group performance}

To map variability in the groups' performance, the first author watched the recordings several times and discussed the recordings with the second author. Afterwards, it became evident that there was a need to systematically document the variability among the nursing groups. Therefore, the groups' 
performance was scored according to the procedural guide- ing ${ }^{[24]}$ (see Table 1). The groups were scored for whether or lines outlined within the technological tool. Specifically, the not they implemented a step, and if the steps were performed procedural guidelines included 30 steps and were outlined in in the correct order, with the correct execution. The scoring accordance with the Norwegian Practical Procedures in Nurs- was conducted by the first author.

Table 1. Overview of group scores on wound care and dressing scenario

\begin{tabular}{|c|c|c|c|c|c|c|c|}
\hline \multicolumn{8}{|l|}{ Overview of group score on wound care and dressing scenario } \\
\hline Procedural steps & Gr1 & Gr2 & Gr3 & Gr4 & Gr5 & Gr6 & Gr7 \\
\hline 1. Inform patient & $\mathrm{x}$ & $\mathrm{x}$ & $\mathrm{x}$ & $\mathrm{x}$ & $\mathrm{x}$ & $\mathrm{x}$ & $\mathrm{x}$ \\
\hline 2. Prepare all necessary equipment & $\mathrm{x}$ & & $\mathrm{x}$ & & $\mathrm{x}$ & & \\
\hline 3. Ensure comfortable position for patient & & & & $\mathrm{x}$ & $\mathrm{x}$ & $\mathrm{x}$ & $\mathrm{x}$ \\
\hline 4. Hand disinfection & & $\mathrm{x}$ & & $\mathrm{x}$ & $\mathrm{x}$ & $\mathrm{x}$ & $\mathrm{x}$ \\
\hline 5. Clean gloves, disposable apron & & $\mathrm{x}$ & $\mathrm{x}$ & $\mathrm{x}$ & $\mathrm{x}$ & $\mathrm{x}$ & $\mathrm{x}$ \\
\hline 6. Remove old zink cream & & & & $\mathrm{x}$ & & & $\mathrm{x}$ \\
\hline 7. Change gloves & & $\mathrm{x}$ & $\mathrm{x}$ & & & $\mathrm{x}$ & $\mathrm{x}$ \\
\hline 8. Irrigate wound & $\mathrm{x}$ & $\mathrm{x}$ & $\mathrm{x}$ & $\mathrm{x}$ & & $\mathrm{x}$ & $\mathrm{x}$ \\
\hline 9. Wash, rinse and dry the foot/leg & $\mathrm{x}$ & $\mathrm{x}$ & $\mathrm{x}$ & & $\mathrm{x}$ & $\mathrm{x}$ & $\mathrm{x}$ \\
\hline 10. Bring the wound irrigation solution to room temperature & & & & & $\mathrm{x}$ & $\mathrm{x}$ & $\mathrm{x}$ \\
\hline 11. Soak gauze pads with irrigation solution and apply to the wound & $\mathrm{x}$ & $\mathrm{x}$ & $\mathrm{x}$ & $\mathrm{x}$ & $\mathrm{x}$ & $\mathrm{x}$ & $\mathrm{x}$ \\
\hline 12. Cover the soaked gauze pads with a clean towel and wait 15 min & $\mathrm{x}$ & $\mathrm{x}$ & $\mathrm{x}$ & & $\mathrm{x}$ & $\mathrm{x}$ & $\mathrm{x}$ \\
\hline 13. Remove unwanted debrits with scalpel & $\mathrm{x}$ & & $\mathrm{x}$ & $\mathrm{x}$ & $\mathrm{x}$ & $\mathrm{x}$ & \\
\hline 14. Gently dry off wound edges with gauze & & & $\mathrm{x}$ & $\mathrm{x}$ & $\mathrm{x}$ & $\mathrm{x}$ & \\
\hline 15. Apply zink cream to wound edges & & & $\mathrm{x}$ & $\mathrm{x}$ & $\mathrm{x}$ & $\mathrm{x}$ & $\mathrm{x}$ \\
\hline 16. Apply wound gel to the wound bed & $\mathrm{x}$ & $\mathrm{x}$ & $\mathrm{x}$ & $\mathrm{x}$ & $\mathrm{x}$ & $\mathrm{x}$ & $\mathrm{x}$ \\
\hline 17. Apply moisturizer to leg/foot & & & $\mathrm{x}$ & $\mathrm{x}$ & $\mathrm{x}$ & $\mathrm{x}$ & \\
\hline 18. Apply correct bandage (Polyurethane foam) & & $\mathrm{x}$ & $\mathrm{x}$ & $\mathrm{x}$ & $\mathrm{x}$ & $\mathrm{x}$ & \\
\hline 19. Fixate foam with wide mesh cotton gauze & $\mathrm{x}$ & $\mathrm{x}$ & $\mathrm{x}$ & & $\mathrm{x}$ & $\mathrm{x}$ & $\mathrm{x}$ \\
\hline 20. Dispose of gloves & & & $\mathrm{x}$ & & & $\mathrm{x}$ & \\
\hline 21. Hand disinfection & & & $\mathrm{x}$ & & & $\mathrm{x}$ & \\
\hline 22. Ensure normal position of the foot; lightly bend nee, $90^{\circ}$ ankle & & & $\mathrm{x}$ & & & & \\
\hline 23. Cover skin from toes to knee with tubular bandage & $\mathrm{x}$ & $\mathrm{x}$ & $\mathrm{x}$ & & & & \\
\hline 24. Apply padding from toes to knee & $\mathrm{x}$ & $\mathrm{x}$ & $\mathrm{x}$ & $\mathrm{x}$ & & & \\
\hline 25. Select correct type of elastic bandage & & $\mathrm{x}$ & & & & & \\
\hline 26. Apply elastic bandage & $\mathrm{x}$ & $\mathrm{x}$ & $\mathrm{x}$ & $\mathrm{x}$ & & & \\
\hline 27. Even pressure/uniform tension & $\mathrm{x}$ & $\mathrm{x}$ & $\mathrm{x}$ & $\mathrm{x}$ & & & \\
\hline 28. Ensure there are no folds and creases & $\mathrm{x}$ & $\mathrm{x}$ & & $\mathrm{x}$ & & & \\
\hline 29. Discuss observations (minimum 6) & & & $\mathrm{x}$ & & $\mathrm{x}$ & $\mathrm{x}$ & \\
\hline 30. Discuss further/new actions (minimum 3) & & & $\mathrm{x}$ & & $\mathrm{x}$ & $\mathrm{x}$ & \\
\hline 31. Total score & 14 & 17 & 24 & 17 & 18 & 21 & 14 \\
\hline
\end{tabular}

\subsubsection{Influencing factors}

The first and second authors conducted a thematic analysis of the data material inspired by Braun and Clarke ${ }^{[25]}$ to describe factors influencing the groups' use of the tool. The thematic analysis follows Braun and Clark's six phases described in Table 2.

The purpose of the narratives in the sixth step was to give an Published by Sciedu Press impression of the relevant aspects, not to present an absolute presentation of all activities. ${ }^{[26]}$ The narratives are verbatim transcriptions of conversations and are accompanied by behavioral and context-specific descriptions; this was done to illustrate the complexity of the interaction. ${ }^{[21]}$ Although all transcriptions were kept verbatim, some of the narratives were shortened for clarity. 
Table 2. Description of the thematic analysis process

\begin{tabular}{|c|c|c|}
\hline Phase & Description & Participants \\
\hline $\begin{array}{l}\text { 1. Familiarizing yourself } \\
\text { with your data }\end{array}$ & $\begin{array}{l}\text {-Familiarization yourself with the data by watching the entire video material } \\
\text { several times } \\
\text { - Mapping initial ideas and thoughts through the process }\end{array}$ & First author \\
\hline $\begin{array}{l}\text { 2. Generating initial } \\
\text { codes }\end{array}$ & $\begin{array}{l}\text {-Initial coding, marking of the segments of interest using Atlas.ti } \\
\text {-Suggestions for initial themes } \\
\text {-Verbal transcriptions of all coded segments to be able to sort through the } \\
\text { data set (author 1) }\end{array}$ & $\begin{array}{l}\text { First and second author } \\
\text { separately }\end{array}$ \\
\hline 3. Searching for themes & $\begin{array}{l}\text { Author discussions, comparing and revising themes. The first author } \\
\text { identified four themes, and the second authors identified five themes. Four } \\
\text { out of five themes matched with regard to content. All themes were revised } \\
\text { to arrive at four common themes. }\end{array}$ & First and second author \\
\hline 4. Reviewing themes & $\begin{array}{l}\text {-Reorganizing video segments linking video segments to the four themes } \\
\text {-Collaboratively watching a randomly chosen selection of the video } \\
\text { segments the first author had connected to each theme, making sure both } \\
\text { authors had a similar understanding of the content of the themes to ensure } \\
\text { validity }\end{array}$ & First and second author \\
\hline 5. Defining and naming & $\begin{array}{l}\text { Theme names were refined and revised, making sure they reflected the } \\
\text { content }\end{array}$ & First and second author \\
\hline 6. Producing narratives & $\begin{array}{l}\text { Video narratives from segments of the data material were produced to } \\
\text { exemplify the contents of each theme }\end{array}$ & First and second author \\
\hline
\end{tabular}

\section{Results}

First, variability in group performance while using the technological tool is presented via the presentation of the groups' scores with associated descriptions of the findings. Second, descriptions of four factors influencing the groups' ability to utilize the technological tool are presented; these were: level of competence, motivation to learn, role clarification, and collaborative problem solving.

\subsection{Variability in nursing groups' performance}

Variability in the groups' performance was mapped by scoring their performance according to the 30 steps (see Table 1).

Only three of the 30 steps were performed by all of the groups: inform patient (step 1); soak gauze pads with irrigation solution and apply to wound (step 11); and apply wound gel to the wound bed (step 16). Five of the steps were performed by six of the groups: clean gloves, disposable apron (step 5); irrigate wound (step 8); wash rinse and dry foot/leg (step 9); cover the soaked gauze pads with a clean towel (step 12); and fixate foam with wide mesh cotton gauze (step 19). Select the correct type of elastic bandage (step 25) and ensure normal position of the foot before applying the bandage (step 22) were performed by one of the groups; this suggests that these steps were the most challenging for the students. Difficult steps also included: remove old zinc cream (step 6), hygiene concerning disposal of gloves (step
21), and hand disinfection (step 22) after cleaning the wound. Although it is difficult to rank the importance of the steps in the wound care and dressing procedure, the general importance of following hygienic guidelines was a challenge for most students throughout the scenario. As shown in Table 1 , substantial variation occurred in the groups' performance, which was linked to several group factors; these are outlined below.

\subsection{Factors influencing nursing groups' ability to utilize the technological tool}

The groups' variability in performance was linked to four influencing factors. These were dominant in the highperforming groups and were lacking or highly variable in the lower-performing groups.

\subsubsection{Level of competence}

Students' level of competence influenced their ability to make use of the information they received through the tablet. Descriptions on the tablet regarding what equipment the students should use and when they should use it were of no use if students were unable to link the specific technical nursing terms to correct actions or the generic names of the correct equipment.

Narrative 1: The instructor sits next to the bed holding the tablet, reading what is listed as the next step of the procedure: '.. and now... tubular bandage, (...) do you have that?' The 
student picks up the tubular bandage, turns toward the instructor: 'Like this?' Instructor: 'No...' the instructor looks over toward the equipment trolley, while the student quickly picks up a gauze bandage roll: 'This?' Instructor: 'Yes, that's the one!' (Group 2, 02.49).

Insufficient knowledge, where one student misleads another, often caused mistakes and consequential flaws later in the scenario. Students with less knowledge of basic principles lacked the ability to see their own flaws, which caused them to misinterpret the instructions from the tablet, deviate from the instructions, and question the sequence of the procedural steps:

Narrative 2: The student starts unpacking the polyurethane foam bandage when the instructor interrupts her: 'Hmm... now it (the tablet) says "perform hand disinfection." She blows her nose and makes a snorting sound together with a fake laughter. 'But you did that earlier!' The student rolls her eyes, raising her eyebrows but continues unpacking the dressing. The instructor continues watching the tablet, using her index finger to scroll back and forth on the screen .'Eh....No! Now something came.....eh...' Her voice fades away, the instructor sighs, the student stops unpacking the dressing and drops her hands down by her side (Group 1, 08.22).

With the tablet at their side, the students did not need to be fluent in the procedural steps; however, they needed to be able to detect errors by integrating their own knowledge with the information from the tablet. As depicted in the next narrative, the tablet could confirm the next correct step, while the instructor's knowledge prevented using the wrong equipment.

Narrative 3: Student: 'Then I'll apply some zinc.' Turns to the equipment trolley to find the cream. While she reaches her hand out, the instructor, who has been reading on the tablet, interrupts her: 'Wasn't it the irrigation solution next...? You know inside the...' She pretends to be holding a bottle in her hand, turning it upside down and squeezing something out of it; she squints her eyes a little bit and looks at the student with raised eyebrows and a question in her eyes. 'That's maybe what you meant, wasn't it?' The student stops with her right hand in the air, pointing at the wound with her left hand and asks: 'Before applying the zinc around it... ?'
Instructor: 'Yeah! Mm!' (... ) She smiles and nods, looks down at the tablet for reassurance, and nods again. When the student picks up the wound gel, the instructor looks back up at the student and sees what she is holding: 'Eh... no! The... you know (looks down at the tablet) the irrigation solution with the gauze and ....' The student puts down the wound gel, rolls her eyes, and sighs: 'Oh! Yes! Yes of course!' She picks up the irrigation solution and starts soaking the gauze; the instructor registers her action in the tablet (Group 6, 10.44).

The student demonstrated that her knowledge of the equipment, knowledge of how to use the irrigation solution, and the reassurance from the tablet came together to ensure the right performance. Therefore, for the groups to utilize the technological tool, they need to possess a minimum level of technical nursing competence and of the clinical skills when training with a technological tool.

\subsubsection{Motivation to learn}

Group motivation for use of the technology-based learning tool influenced students' ability to use the technology. Motivation was displayed through a combination of verbal and nonverbal expressions that were interpreted as the groups' motivation to learn. There was a positive atmosphere in the motivated groups, which was shown both through nonverbal and verbal excitement when interacting with the tablet.

Narrative 4: Student: 'Okay, then I'll just put the irrigation solution on the gauze...' Instructor: 'Mm, yes.' The instructor nods before looking down at the tablet, then quickly looks up again saying: 'Aha! Okay! It actually says here that you are to heat the solution to room temperature!' The instructor points at the tablet while looking at the student with surprise. Student: 'Okay, yeah that must be the same principle as not cooling down the wound, right?' Instructor: 'Yes! Yeah, right! That must be it. Okay good then we figured that one out' (Group 6, 6.38).

The groups with a high level of motivation displayed more interest in finding the correct action; they appeared to want to understand and learn as much as possible. They often expressed comments like 'hmm... that's interesting' and 'good for us to know' with excitement and wonder. This gave the impression that the training was valuable and that students perceived the tablet as a resource for accelerating their learning. The groups' level of motivation was often 
detected within the first couple of minutes of the video and remained the same throughout the entire scenario.

Groups with high levels of motivation generally had high levels of activity, discussions, and questions; however, groups with low levels of motivation demonstrated low interest in the activity and made few gestures indicating interest in the quality of their performance.

Narrative 5: While applying the elastic bandage, the student says in a monotone voice: 'When applying the elastic bandage it is important to overlap by approximately $50 \%$ and make it smooth, preventing folds and creases.' The instructor nods, 'mmm-hmm', while avoiding looking at the student's actions. The student continues applying the elastic bandage without overlapping and with several folds and creases present on the bandaged leg (Group 2, 20.33).

These groups also expressed low levels of problem solving, had a low frequency of critical questions, and appeared to be low or non-responsive toward questions from the instructor.

Narrative 6: The instructor reads from the tablet while the patient lies in bed, arms crossed over her chest, slightly biting her lower lip, and stirring at the bedcover. The student leans on to the bed with her left hip and arm, looking at the instructor with an empty stare. Instructor: 'What is the difference between infection and inflammation?' The student looks over to the patient and raises her eyebrows. The patient furrows her eyebrows, still staring at the bedcovers while asking: 'What?' Instructor: 'The difference between infection and inflammation.' Silence for six seconds. Instructor: 'C'mon, you know this, guys!' The student stares up toward the ceiling. After four seconds, the patient says 'eh... hmm. I don't believe I have heard that word before? Inflammation...?' while looking over at the student who stares out the window (Group 4, 21.41).

Higher levels of motivation generally caused a higher level of activity within the group; this lead the groups to seek more answers, engage in more discussions, and become more interested in finding the right action. Therefore, high levels of motivation increased the groups' ability to utilize the technological tool.

\subsubsection{Role clarification}

Students' use of technology was also influenced by the way they interpreted their roles. The students were not given any strict guidance about how to perform the task; they interpreted their roles differently. This diversity seemed to affect group performance. The instructors in the lower- and middle-performing groups interpreted their role as strict observers, where their task was to simply register what the student performed.

Video narrative 7: The student puts a new glove on her right hand, picks up the zinc cream, throws a quick glance at the instructor, and says, 'Maybe I should apply some moisturizer first... I'm not really sure...?' The instructor looks at her while the question is asked, blinks once, and then looks down at the tablet again without answering the question. The student lingers for a couple of seconds, looks at the instructor and down at her foot; when nothing happens, she continues with the zinc cream (Group 2, 15.41).

The lack of confirmation from the instructor often caused student uncertainty and hesitation, which lead to fewer questions and interactions. Instructors in the lower-performing groups also had a tendency to focus on the tablet, rather than following the pace and progress of the student. This often threw the student off balance, creating disturbance and confusion during the training session.

Video narrative 8: While beginning to remove debris with a scalpel, the student glances at the patient and explains, 'This is a sharp knife that I use to remove some dead cells and debris. Let me know if it hurts, okay?' Patient: 'Okay, that's fine (...) Does the wound look better than last time?' Student: 'Hmm? Yes, it looks better than yesterday.' Student and patient exchange looks and smile. The instructor during this sequence is occupied with the tablet, scrolling back and forth, reading. She now interrupts the other two with a high-pitched voice: 'Here there is a question about washing (reads the question aloud). Have you washed the wound yet? Should you wash it now?' The student answers with a calm voice while continuing what she is doing: 'I'm removing debris with the scalpel.' Turning to the patient, she continues: 'I'm now going to irrigate the wound.' She picks up a jug of water. The instructor flickers and glances back and forth from the tablet to the student: 'How warm is that fluid?' Both the patient and student answer: 'Body temperature'. (...) Instructor, still flickering her eyes: 'What?! Do you use water? That's not what it says here. 
Is this thing wrong? Are they using irrigation solution while we use water...? (...) I don't understand.' (Group 4, 04.54).

In the high-performing groups, there was an understanding that everyone's role was to contribute when they could, with what they could; this resulted in the students helping and guiding each other, which allowed for the best option for handling the situation. Although they all had different roles (i.e., student, patient, instructor), they all contributed. The role of guiding and helping was for all members of the group. This role alternated between the participants, and depended on who possessed the most knowledge at any given time during the scenario.

Video narrative 9: Instructor: 'Padding?' Student, turning toward the equipment trolley, gazing over the entire table: '...padding...? Padding....' Patient: 'Yes, (points to the right side of the table) it's the one you know... you wrap around the leg.' Student looks over to the right side and picks up the elastic bandage: 'Oh, yes! This?' The instructor looks up at the student and firmly nods his head. The patient who has had his back to the student all this time now turns toward the student and says: 'No, no it's the other one underneath the elastic bandage.' Student, holding up the padding: 'Okay, this?' The patient nods and then looks at the instructor: 'Agree?' Instructor: 'Yes, that's the one.' (Group 5, 03.52).

Therefore, role clarification entailed that every participant understood that their role was to contribute with what they knew, as long as it was for the benefit of the group. The participants in the lower-performing groups saw their role as controlling or strictly observing; however, the higher-performing groups perceived that everyone had a contributing role.

\subsubsection{Collaborative problem solving}

Group utilization of the technological tool also affected their ability to detect and solve problems during the scenario. The groups asked critical questions, problematized, and discussed issues prior to coming to a consensus about what to do; this allowed them to often detect and solve problems before they arose. These groups often consulted the tablet and used their own prior knowledge to find answers, which resulted in higher scores on the skill performance assessment. In addition, the instructor or the patient tried to help the student find appropriate answers more frequently; this was done by offering tips and hints; preventing incorrect steps; and encouraging the student to find her own answers.

Published by Sciedu Press
Video narrative 10: The student picks up the tube of zinc cream, scrutinizes it, and starts applying it to the wound while she asks: 'This is the zinc thing, isn't it?' The instructor looks up from the tablet, nods her head, smiles, and says: 'Yes, that's the zinc cream'. The student, while deeply concentrating on applying the cream, says: '.. zinc cream... why do we apply that...? It is to....?' Her voice fades away. The instructor is silent at first, looks down at the tablet, seems occupied with reading, but looks up at the student, leans back in the chair, and smiles: 'Yeah, the zinc-what was that supposed to do...? With the edge of the wound...?' Student: 'What?... eh... is to preserve... eh... I don't know...' Instructor: 'Actually, it is to preserve the edge of the wound, so it doesn't get wet, because... eh... yes...' The student interrupts: 'Yes! Don't get it wet! That was it!' The instructor looks down at the tablet again and presses a button on the screen to register the fact that the student is applying the zinc cream when a question pops up on the screen: 'It actually says here to ask you where we apply the zinc cream and why. There is also some additional information. Let me see...' (Group 3, 10.58).

Lower-performing groups lacked the ability to detect a problem; they were less critical and moved forward without detecting their own errors. These groups seldom questioned anything connected to the instructions or their own performance. If a problem was detected, they tended to skip the section where the problem occurred entirely, moving forward to the next section of the scenario. When answers were provided on the tablet, the answer was read aloud without reflection or discussion. Reflective questions, where the tablet did not provide any answers, were completely skipped. If a discrepancy occurred between their own beliefs and the information or instructions on the tablet, the students in the lower-performing groups often trusted their own instincts rather than the information on the tablet.

Video narrative 11: Student: 'Okay, then we put on the moisturizer. Does the tablet say anything about that?' Instructor: 'Hmm... It says, "Bring the wound irrigation solution to room temperature"...' Patient: 'Eh... but this is what we have learned so...' Instructor: 'Yes, put on some moisturizer.' After applying the cream, the student asks: 'So, now I change gloves? No?' Instructor: 'Well, it said earlier that you were to change gloves (...), but 
that's not what we are doing now, so that doesn't count.' Both the student and patient nods, moving forward with the same gloves (Group 1, $5.09)$.

Collaborative problem solving included being critical of one's own understanding, reaching a consensus based on all members' opinions, and discussing ways to find an answer in collaboration with the group. Although the combination of these actions did not guarantee finding the right answers, it helped the groups detect their own flaws, and kept them from misinterpreting the information that could result in a poor performance.

\section{DisCUSSION}

In the current study, nursing students' use of a technologybased learning tool was examined. The variability of the groups' clinical skill performance was mapped; this resulted in a description of factors that influenced the groups' ability to use the technological tool. In the following subsections, we discuss issues that cut across the identified factors.

\subsection{Interconnectivity}

During the analysis, it was difficult to isolate the different factors affecting the students performance. In almost every selected segment of the recordings, at least two of the factors occurred simultaneously. Competence was connected to student motivation to learn and develop problem-solving skills Moreover, the ability to connect previous knowledge with new knowledge and solve the problems fueled additional student motivation. In addition, role fulfillment was closely intertwined with students' level of knowledge. This was linked to their problem-solving skills. The instructors had trouble making use of the information on the tablet if they did not have previous knowledge; this made it difficult for them to guide and help the students. However, knowledgeable instructors combined their knowledge with the information on the tablet to help guide the student through the scenario. This created discussions, engagement, and opportunities to problem solve collaboratively as a group. The interconnectivity between the factors seemed to be closely related to the members of the group and their interactions. Although many groups gave the impression of task mastery, some groups worked together better than others. Role clarification, motivation to learn, and use of one's own competence to collaboratively solve problems was apparent in the high-performing groups. However, the low-performing groups struggled with all of these aspects. Given the natural diversity in group members' personality, preferred learning styles, and experiences, it is reasonable to believe that diversity influences the group dynamic and subsequent performance. ${ }^{[27]}$

\subsection{Group dynamics}

Since group dynamics influence group performance, the findings presented herein are likely related to group dynamics. Several studies have pointed out that nursing faculty fail to attend to group dynamics. ${ }^{[27,28]}$ According to Jaques, ${ }^{[29]}$ a key attribute of a group is the possession of shared aims, agreed rules, and determined power relations. As shown in our study, some of the lower-performing groups struggled to solve problems collaboratively when one member was dominant but had a low level of competence. This seemed to steer the group in the wrong direction. This could be seen as a consequence of poor group dynamics where the lack of a shared aim and a skewed power structure affected the group's motivation. ${ }^{[30]}$ Relatedly, the high-performing groups displayed a positive dynamic between the group members; specifically, one of the members' enthusiasm rubbed off on the other participants. The literature demonstrates that group work is a powerful arena for peers to motivate their less motivated students. ${ }^{[27]}$ Therefore, groups should ideally be composed of both students who are more and less motivated. This would allow for the more motivated individuals to positively influence the other students. Although group members' attributes can positively affect the group dynamics, they can also negatively affect outcomes. The lack of role clarification may be a reason why some of the groups developed poor group dynamics. Role clarification within a simulation is an essential part of pre-briefing, and is crucial for maximizing benefits to students from the learning situation. However, a lack of clarified roles causes confusion and frustration among students. ${ }^{[31]}$ In the current study, participants were not provided with clearly defined roles because the goal was to see how they solved the problem themselves. This was not problematic in the high-performing groups, but in the lower-performing group, the group dynamics could have been improved through clarifying individual roles during pre-briefing. Group work is used extensively in nursing education. It fosters active, deep collaborative learning. However, positive group processes are dependent on recognition an accommodation of group dynamics. ${ }^{[27,30]}$ Therefore, nursing education programs that use group work must facilitate positive group processes.

\subsection{Technology confidence}

In the lower-performing groups, a lack of motivation was evident through low interaction, disengagement during the situation, and participants' nonverbal expressions indicating disinterest (e.g., looking away and rolling their eyes). This lack of motivation was accompanied by a general distrust toward the technology. These participants often muttered comments that something was wrong with the technology, or that they believed the content on the technological tool was 
wrong. Several studies have reported that faculty members modelling behaviors during technology adoption is important for student use of technology. Specifically, studies indicate that distrust in technology is linked to a lack of role modeling. ${ }^{[15]}$ At the end of the clinical skills course, the teachers examined students' clinical skills. Teachers' attitudes toward the technology may mirror the students' beliefs and trust in the technology. Since faculty members have different exposure and awareness of the technological learning tool, it is reasonable to believe that they hold different perspectives about the technology and model its use differently. During the clinical skills course, the groups were in contact with different faculty members, which could explain the group differences in expressed confidence. Some students expressed clear confidence in the answers and information provided by the tablet; however, other students appeared to distrust the technology and blamed it if something went wrong. Therefore, role modeling from faculty may have contributed to increased technology confidence among students, which has been found in previous research. ${ }^{[32,33]}$

\subsection{Limitations}

The results of this study were based on data from student groups from one nursing school and examined a particular technology-based tool which limits the transferability to other technology-based learning tools. Douglas ${ }^{[34]}$ asserted that all groups have some inherent similarities. Thus, the results presented herein are valuable for understanding other group-based, technology-based learning tools. During the first part of the analysis, the first author scored the groups' performance according to the practical procedure guidelines; however, it could be argued that different scorers could result in different results. Nevertheless, the same author scored all of the scenarios, which contributed to consistency.

\subsection{Implications}

Faculty must facilitate both students' and staffs' technology use. Students must possess collaborative problem-solving skills early in their education to enable them to integrate different sources of information. Students must also be prepared to use technological tools. This can be accomplished by preparation via learning experiences, possessing a mini- mal level of competence, having a common group aim, and the clarification of roles. Faculty who introduce group-based learning methods must be aware of how group dynamics can affect group outcomes, and must strive to facilitate positive group processes via teacher preparation. This should be done by ensuring faculty's knowledge of group dynamics and group composition. While it is difficult to implement, a mixture of more and less motivated students it is advisable as motivated students positively influence others in their group.

\section{Conclusion}

Previous studies have addressed issues regarding the challenges with technology implementation. This study investigated how groups of nursing students utilize a previously implemented technology-based learning tool. The results indicated that there was a large variability in students' performance in a selected procedure (i.e., wound care and dressing; scores ranged from 14 to 24 out of 30) and their ability to utilize the technological tool. These differences were associated with the four group factors: level of competence, motivation to learn, role clarification, and collaborative problem-solving skills. While these factors cannot provide an exhaustive explanation of variability in performance, they help explain the group differences in the ability to use the tool. Faculty must continue to actively seek knowledge about what inhibits effective technology use. In addition, they should facilitate technology use to ensure positive outcomes associated with technology-based learning methods. Currently, there is inconsistency in the literature regarding whether technology-based learning is superior to traditional learning; however, the results of this study outline factors that may better prepare students to utilize technology and, as a result, benefit from its effectiveness.

\section{ACKNOWLEDGEMENTS}

The authors would like to express their gratitude to all students who participated in the study and the faculty members for their collaboration.

\section{CONFlicts of InTEREST Disclosure}

The authors declare that there is no conflict of interest.

\section{REFERENCES}

[1] Seckman CA. Perceived sense of community, cognitive engagement, and learning outcomes among undergraduate nursing students enrolled in an internet-based learning course. Comput Inform Nurs. 2014; 32(10): 482-9. http://dx.doi.org/10.1097/cin. 00000 00000000076

Published by Sciedu Press
[2] Button D, Harrington A, Belan I. E-learning \& information communication technology (ICT) in nursing education: A review of the literature. Nurse Education Today. 2014; 34(10): 1311-23. http://dx.doi.org/10.1016/j.nedt.2013.05.002

[3] Ross JG. Simulation and psychomotor skill acquisition: A review of the literature. Clinical Simulation in Nursing. 2012; 8(9): e429-e35. 
http://dx.doi.org/10.1016/j.ecns.2011.04.004

[4] Black A. Gen Y: Who they are and how they learn. Educational Horizons. 2010; 88(2): 92-101.

[5] Montenery SM, Walker M, Sorensen E, et al. Millennial generation student nurses' perceptions of the impact of multiple technologies on learning. Nursing Education Perspectives. 2013; 34(6): 405-9. http://dx.doi .org/10.5480/10-451

[6] McCurry MK, Martins DC. Teaching undergraduate nursing research: A comparison of traditional and innovative approaches for success with millennial learners. Journal of Nursing Education. 2010; 49(5): 276-9. http://dx.doi.org/10.3928/01484834-20091217-0 2

[7] Lahti M, Hätönen H, Välimäki M. Impact of e-learning on nurses' and student nurses knowledge, skills, and satisfaction: A systematic review and meta-analysis. International Journal of Nursing Studies. 2014; 51(1): 136-49. http://dx.doi.org/10.1016/j.ijnurst u. 2012.12 .017

[8] River J, Currie J, Crawford T, et al. A systematic review examining the effectiveness of blending technology with team-based learning Nurse Education Today. 2016; 45: 185-92. http://dx.doi .org/1 $0.1016 / j$.nedt . 2016.08 .012

[9] Petty J. Interactive, technology-enhanced self-regulated learning tools in healthcare education: A literature review. Nurse Education Today 2013; 33(1): 53-9. http://dx.doi.org/10.1016/j.nedt. 2012 .06 .008

[10] Lashley M. Faculty forum. Teaching health assessment in the virtual classroom. Journal of Nursing Education. 2005; 44(8): 348-50. PMid:16130340

[11] Mundy CA. Innovative teaching strategies: Educating student nurses on vascular access management. Journal of the Association for Vascular Access. 2007; 12(4): 232-6. http: //dx.doi.org/10. 2309 /java.12-4-11

[12] Guise V, Chambers M, Välimäki M. What can virtual patient simulation offer mental health nursing education? Journal of Psychiatric \& Mental Health Nursing. 2012; 19(5): 410-8. http: //dx.doi.org/10.1111/j.1365-2850.2011.01797.x

[13] Gerdprasert S, Pruksacheva T, Panijpan B, et al. An interactive webbased learning unit to facilitate and improve intrapartum nursing care of nursing students. Nurse Education Today. 2011; 31(5): 531-5. http://dx.doi.org/10.1016/j.nedt.2010.10.008

[14] Petit dit Dariel OJ, Raby T, Ravaut F, et al. Developing the serious games potential in nursing education. Nurse Education Today. 2013; 33(12): 1569-75. http://dx.doi.org/10.1016/j.nedt. 2012 .12 .014

[15] Raman J. Mobile technology in nursing education: where do we go from here? A review of the literature. Nurse Education Today. 2015; 35(5): 663-72. http://dx.doi.org/10.1016/j.nedt. 2015.0 1.018

[16] Petit dit Dariel O, Wharrad H, Windle R. Exploring the underlying factors influencing e-learning adoption in nurse education. Journal of Advanced Nursing. 2013; 69(6): 1289-300. http://dx.doi.org /10.1111/j.1365-2648.2012.06120.x

[17] Petit dit Dariel O, Wharrad H, Windle R. Using Bourdieu's theory of practice to understand ICT use amongst nurse educators. Nurse Education Today. 2014; 34(11): 1368-74. http://dx.doi.org/1 $0.1016 / j \cdot$ nedt .2014 .02 .005
[18] Warren JN, Luctkar-Flude M, Godfrey C, et al. A systematic review of the effectiveness of simulation-based education on satisfaction and learning outcomes in nurse practitioner programs. Nurse Education Today. 2016. 46: 99-108. http://dx.doi.org/10.1016/j.ned t.2016.08.023

[19] Verkuyl M, Atack L, Mastrilli P, et al. Virtual gaming to develop students' pediatric nursing skills: A usability test. Nurse Education Today. 2016; 46: 81-85. http://dx.doi.org/10.1016/j.nedt. 2016.08 .024

[20] Polit DF, Beck CT. Essentials of nursing research: appraising evidence for nursing practice. Philadelphia: Wolters Kluwer/Lippincott Williams \& Wilkins; 2010. 610 p.

[21] Derry SJ, Pea RD, Barron B, et al. Conducting video research in the learning sciences: guidance on selection, analysis, technology, and ethics. Journal of the Learning Sciences. 2010; 19(1): 3-53. http://dx.doi.org/10.1080/10508400903452884

[22] Haraldseid C, Friberg F, Aase K. Nursing students' perceptions of factors influencing their learning environment in a clinical skills laboratory: A qualitative study. Nurse Education Today [Internet]. 2015. http://dx.doi.org/10.1016/j.nedt.2015.03.015

[23] Haraldseid C, Friberg F, Aase K. How can students contribute? A qualitative study of active student involvement in development of technological learning material for clinical skills training. BMC Nursing. 2016; 15(1): 1-10. http://dx.doi.org/10.1186/s12 912-016-0125-y

[24] PPS [Internet]. Practical procedures in nursing. Oslo: Cappelen Damn; 2014 [cited 2014 May 8] Available from: http: //www.pp snett.no

[25] Braun V, Clarke V. Using thematic analysis in psychology. Qualitative Research in Psychology. 2006; 3(2): 77-101. http://dx.doi .org/10.1191/1478088706qp063oa

[26] Heath C, Hindmarsh J, Luff P. Video in qualitative research. London: Sage Publications; 2010. 175 p.

[27] Jackson D, Hickman LD, Power T, et al. Small group learning: Graduate health students' views of challenges and benefits. Contemporary Nurse: A Journal for the Australian Nursing Profession. 2014; 48(1): 117-28. http://dx.doi.org/10.5172/conu.2014.48.1.117

[28] Cook SH, Matheson H. Teaching group dynamics: a critical evaluation of an experiential program. Nurse Education Today. 1997; 17(1): 31-8.

[29] Jaques D. Learning in groups: A handbook for improving groupwork. 3rd ed. London: Kogan Page; 2001. 311 p.

[30] Davies WM. Groupwork as a form of assessment: common problems and recommended solutions. Higher Education. 2009; 58(4): 563-84. http://dx.doi.org/10.1007/s10734-009-9216-y

[31] Harder N, Ross CJM, Paul P. Student perspective of roles assignment in high-fidelity simulation: An ethnographic study. Clinical Simulation in Nursing. 2013; 9(9): e329-e34. http://dx.doi.org/10. 1016/j.ecns. 2012.09.003

[32] Beard KV, Greenfield S, Morote ES, et al. Mobile technology: lessons learned along the way. Nurse Educator. 2011; 36(3): 103-6. http://dx.doi.org/10.1097/NNE.0b013e3182161016

[33] Swan BA, Smith KA, Frisby AJ, et al. Evaluating tablet technology in an undergraduate nursing program. Nurse Education Perspective. 2013; 34(3): 192-3.

[34] Douglas T. Groups: understanding people gathered together. London: Travistock Publications; 1983. 380 p. 